\title{
Encoding present situations in Mandarin Chinese and isiXhosa: A comparative study
}

\author{
Xiujie Ma and Silvester Ron Simango* \\ Department of English Language and Linguistics, Rhodes University, South Africa \\ Email: maxiujie16@gmail.com,r.simango@ru.ac.za
}

\begin{abstract}
This study sought to investigate how two typologically distinct languages, Mandarin and isiXhosa, deal with the encoding of temporal relations by focusing on a specific time frame the present. The study revealed that both Mandarin and isiXhosa do not have overt grammatical features for locating situations in the present, suggesting that the present is the unmarked or default temporal location in both languages. However, the study also revealed that the two languages differ in at least two significant respects. First, the two languages differ with respect to the extent to which they distinguish ongoing situations from habitual ones when their temporal location overlaps with the present moment: it was found that whilst Mandarin makes this distinction unequivocal through the use of distinct particles, isiXhosa forms are generally (though not always) equivocal and the distinctions have to be made lexically (through the use of temporal adverbials) or through context. Second, the study revealed that the two languages differ in terms of how they encode the present state and its relation to a previous state. In Mandarin, a current state is invariably described in terms of its relation with a previous state, i.e. whether it is contrastive to some previous state or if the state has some duration which includes the present moment. In isiXhosa a current state is sometimes described in terms of the result of a previous event; in other cases, a current state is described without any indication of whether or not it is related to a previous state. The study concludes that Mandarin places more emphasis on situation-internal properties of states/events in conveying temporal relations, whereas isiXhosa places more emphasis on the temporal locations themselves.
\end{abstract}

Keywords: tense, aspect, Bantu, Mandarin, comparative linguistics

\section{Introduction}

All languages have ways of locating the time in which situations occur or exist. Reference to time can take various forms, some of which are shared across languages and others which are unique to a particular language (Levinson 1983). Temporal relations can be lexically encoded through temporal adverbials, for example, or alternatively they can be grammatically encoded through the use of tense and aspect. In all likelihood, all languages have temporal adverbials that locate situations in time (Comrie 1976), however, there is no guarantee that all languages

\footnotetext{
* Corresponding author.
} 
have the same grammatical resources for encoding temporal relations. Comrie observes that languages differ not only in the manner and accuracy in which they encode the location of situations in time but also in "the relative weight assigned to the lexicon and to the grammar in establishing location in time" (Comrie 1985:7). In this study, we investigate the encoding of present situations in two typologically distinct languages - Mandarin Chinese (henceforth Mandarin) and isiXhosa - to ascertain the degree to which these languages might be similar. Mandarin, an isolating language, lacks morphological inflection for expressing grammatical categories such as tense, person, number and case, but exhibits a richness of function words such as particles and auxiliaries that fulfil the various syntactic functions (Wang 1943, Gao 1948, Chao 1968, Ye and Xu 1997). These features of the language have shaped the ways in which Mandarin expresses temporal location of situations. Mandarin typically encodes temporal relations by means of lexical items and particles.

IsiXhosa which, according to Guthrie (1971), belongs to zone S.40 in the classification of Bantu, is an agglutinating language. Bantu languages in general have a high degree of synthesis in forming words. Syntactic functions are primarily expressed by making use of prefixes and suffixes: grammatical categories, such as tense, aspect, negation and mood, are either prefixed or suffixed to the verb stem (for example, see Nurse 2003 and related works cited therein). In isiXhosa, temporal relations are primarily encoded grammatically, that is, by tense/aspect affixes which are attached to the verb; adverbial expressions are, in most cases, redundant features and are only used to make more precise the temporal location of a given situation. Bantu languages in general are renowned for encoding temporal relations through tense systems that are themselves quite robust, with some languages such as Bamileke (Anderson 1983) and iciBemba (Chung and Timberlake 1985) reportedly possessing tenses that number into double figures. Although isiXhosa is not endowed with the same number of tenses as Bamileke or iciBemba, the language does possess a far richer grammatical system for conveying temporal relations compared to Mandarin.

Our interest in choosing the present as the basis for comparing how the two languages encode temporal relationships comes from the fact that it is the temporal region in which the two languages seem to exhibit great similarity (at least superficially) with respect to the strategies used in conveying temporal information. Consider as a starting point the sentences in (1) and (2) ${ }^{1}$ :

$$
\begin{aligned}
& \text { U-njingalwazi Cata u-fundis-a isi-Xhosa. (IsiXhosa) } \\
& \text { CL1-Professor Cata 1SM-teach-FV CL7-Xhosa } \\
& \text { 'Professor Cata teaches/is teaching isiXhosa.' }
\end{aligned}
$$
Cata jiàoshòu jiāo kăosà yǔ.
(Mandarin)
Cata Professor teach Xhosa language
'Professor Cata teaches isiXhosa.'

Note that although the proposition in both sentences is interpreted as being expressed in the present tense, there is no overt tense marker in either (1) or (2) which indicates that the event in question is located in the present time. On this limited evidence, we can assume that both isiXhosa

\footnotetext{
${ }^{1}$ The following abbreviations are used in the glosses: $\mathrm{AGR}=$ agreement; $\mathrm{CL}=$ noun class; $\mathrm{DUR}=$ durative aspect; $\mathrm{FV}=$ final vowel; GEN = genitive; $\mathrm{HAB}=$ habitual; $\mathrm{LOC}=$ locative; PART $=$ participial mood; PERS $=$ persistive aspect; $\mathrm{PM}=$ participial mood; $\mathrm{PRF}=$ perfect; $\mathrm{PROG}=$ progressive; $\mathrm{PRS}=$ present tense; $\mathrm{PST}=$ past tense; $\mathrm{SM}=$ subject marker.
} 
and Mandarin do not have formal properties for encoding present time, or, to put it differently, we can say that in both languages the absence of any formal properties is interpreted as designating a location in the present time. This suggests that the present moment is the unmarked or default time in the grammar of both languages. But the question that arises here is whether the unmarked form has identical values in both isiXhosa and Mandarin, that is, whether (1) and (2) have identical meanings. Note that whereas the sentence in (1) is ambiguous, the one in (2) is not. Specifically, in isiXhosa the sentence can be interpreted to mean (i) that at utterance time (UT) Professor Cata is carrying out the act of teaching, or (ii) that Professor Cata is a career teacher of isiXhosa which means he performs this action on a regular or habitual basis (even though he may not necessarily be doing that at UT). In Mandarin, however, the sentence can only mean that Professor Cata's career is to teach isiXhosa and not that he is carrying out the act at UT. We will return to explicating these subtle differences below. In particular, we would like to establish how the two languages distinguish ongoing events from habitual or regular ones. Furthermore, we seek to establish whether, and the extent to which, the two languages encode situation-internal temporal relations.

\section{Studies of temporal relations}

Studies on how languages encode temporal relations abound in the literature (see for example Wang 1943, Gao 1948, Comrie 1976, Li and Thompson 1981, Comrie 1985, Giorgi and Pianesi 1997, Timberlake 2007, Botne and Kershner 2008, and related works). Although linguistic provision for expressing time is reflected both in the lexicon and in the grammar, most studies focus on the grammatical markers for encoding temporal relations, specifically tense and aspect. Tense, which is marked either by verbal affixation or by functional words adjacent to the verb, is defined by Comrie as the "grammaticalisation of the location in time" (Comrie 1985:9). Tense is deictic in nature and, according to Comrie, takes UT as the reference point or deictic centre. Tense is thus a grammaticalised mechanism that relates UT to the time at which a situation occurs. Typically, tense indicates "situation-external" time (Comrie 1976:5) in the sense that it provides the speakers of a language with a mechanism for indicating whether "the contextual occasion and the reported event are earlier than, or simultaneous with, or later than the here-and-now of speech" (Timberlake 2007:283). The present tense, for example, indicates that the reported situation occurs or exists at a time interval that overlaps with UT. Comrie's position on how tense relates UT to the reported event - specifically, that tense takes UT as the deictic centre - is not universally accepted. Reichenbach (1947), for example, identifies three temporal points, namely "speech time", "event time" and "reference time", and claims that different tenses specify different ordering relations between these three temporal points. Klein $(1992,2000)$ builds on Reichenbach's idea and argues that tense does not relate speech time to event time; it refers instead to the relation between UT and what he calls "topic time", the latter he defines as "the time span to which the claim made on a given occasion is constrained" (Klein 1992:535). Temporally, topic time can be situated before UT (past), or at a time that includes UT (present), or it can be located after UT (future). Importantly, Klein notes that different languages may cluster these temporal relations differently in their grammars.

In contrast to tense, aspect sheds light on the internal composition of a situation. That is, aspect describes "different ways of viewing the internal temporal constituency" of a situation (Comrie 1976:3). Aspect, just like tense, is marked by inflectional affixes on verbs or particles that serve as grammatically required aspectual markers. Importantly, as Comrie (1985) and Binnick (1991) indicate, aspect is non-deictic since the internal temporal constituents of a situation are 
independent of any point on the time line. Aspect is generally categorised as perfective or imperfective: perfective aspect indicates "the view of a situation as a single whole, without distinction of the various separate phases that make up that situation", whereas imperfective aspect "pays essential attention to the internal structure of the situation" (Comrie 1976:16). Imperfective aspect typically consists of habitual and continuous aspect. Continuous aspect is further subdivided into non-progressive and progressive aspect, the specifics of which need not concern us here.

In addition to grammatical aspect described above, there is lexical aspect or "aktionsart", which is captured in Vendler's (1957) classification of situation types. According to Vendler (see also Dowty 1979), verbs have temporal properties which include dynamicity, durativity and telicity. Dynamicity is concerned with whether a situation consists of a series of heterogeneous stages or if a situation is homogeneous from the start to the endpoint. Certain situations occur over an extended time span and are thus durative, whereas other situations are instantaneous and not durative. Telicity, also called "boundedness", refers to whether or not a situation has a built-in endpoint. Based on these temporal properties, Vendler (1957) proposes a fourfold classification of situation types, which is further developed by Kenny (1963) and Dowty (1979): states, activities, accomplishments and achievements. Situation types of the verb interact with tense and aspect. For instance, stative verbs do not have progressive forms since the stativity of the verb would be in conflict with the non-stativity of the progressive (Comrie 1976:35). A detailed discussion of situation types in Mandarin and isiXhosa is beyond the scope of this study, therefore we will only highlight the areas that are pertinent to the expression of present situations. With these general observations, a review of the specific studies on Mandarin and isiXhosa is in order, and it is to this that we now turn.

\subsection{Temporal relations in Mandarin}

Since the early part of the $20^{\text {th }}$ century, the primary debate on temporal expression in Mandarin has been whether or not the language has tense. Some linguists (e.g. Li 1924, Dragunov 1952, Yakhontov 1957, Wang 1981, Zhang 1998 and Li 2002) assert that Mandarin does indeed have tense, while others (e.g. Wang 1943, Gao 1948 and Li and Thompson 1981) argue that Mandarin is tenseless. Linguists who claim that Mandarin is a tense language argue that temporal adverbials as well as the particles zhe, le and guo are the markers of tense. Those linguists who argue that Mandarin is tenseless point out that although temporal adverbials play an important role in expressing temporal location, adverbials are lexical in nature and do not represent a "grammaticalisation of time", which is what tense is supposed to do. They consider the particles zhe, le and guo as aspectual markers rather than tense makers. We sidestep the debate in the present study but note that the controversy surrounding the status of the three particles as tense markers stems from the fact that temporal location of situations denoted by sentences containing any one of these particles is predictable. For example, in the absence of temporal adverbials, a situation marked by zhe is assumed to be located at the present time; a situation marked by le or guo is assumed to be located in the past. This, consequently, gives a strong impression that these three particles are tense markers. However, Smith and Erbaugh (2005) claim that the default interpretation locates ongoing events and states in the present, and perfective events in the past. In other words, these three particles are aspectual markers and the interpretation of temporal location of any situation marked by zhe, le or guo comes from the interaction between situationexternal and situation-internal factors, rather than the inherent meaning of the particles themselves. 


\subsection{Temporal relations in isiXhosa}

Studies on tense and aspect in isiXhosa and related Bantu languages have a long history going from as far back as Doke (1931), McLaren (1936) and Bennie (1939) to, more recently, Louw (1963), Davey (1973), Du Plessis (1978, 1986), Posthumus (1988), Du Plessis and Visser (1992), Nurse (2003, 2007), Botne and Kershner (2008), and other related works. Most studies have focused on the metrical nature of the tense systems in Bantu languages with various tenses showing different degrees of remoteness from UT. In this connection, isiXhosa and other Nguni languages are said to have the following tense/aspect categories: remote past, recent past (also called "perfect"), present, near future and remote future. The tenses which, in the words of McLaren (1936:81), "serve to indicate partly the time and partly the completeness of the verbal action" are categorised into two classes: primary tenses and secondary or compound tenses. Compound tenses are typically formed by combining the auxiliary -be or -ye with a lexical verb in the indicative or participial mood (e.g. ndibe ndithetha 'I have been speaking/ I was speaking') and the tenses are often used to describe ongoing situations, a point we explore further below. It has been noted that the form which is designated as the present tense in isiXhosa has multiple meanings: it may indicate that an action is ongoing at UT, an action usually takes place, or a state exists at the present moment, or, depending on the verb type, it may indicate that an event has just occurred (see, inter alia, Du Plessis 1986 and Posthumus 1988). The present tense, as alluded to above, is morphologically unmarked in most Bantu languages, but has an alternative form in isiXhosa and other Nguni languages - known as the "long form" - in which the prefix -ya- appears on the verb. The long form and short form of the present tense are not distinct as regards the temporal relations they encode, however, as Du Plessis (1986) notes, the long form carries certain aspectual properties such as imperfective (e.g. ndiyahamba ehlatini 'I am walking in the forest') or occasional (e.g. ndiyayinxiba ivesti 'I do put on a vest sometimes'), depending on the type of verb used. Du Plessis further points out that there are certain grammaticality effects for some intransitive isiXhosa verbs such as lila 'cry' and sebenza 'work'. For these verbs, the long form is the only alternative in that the use of the short form results in ungrammatical sentences. It is worth emphasizing that the occurrence of the long form $-y a$ - is largely determined by syntactic factors (e.g. the presence or absence of a nominal object, focus on the verb, etc.) rather than by temporal factors per se.

In many respects, aspect in isiXhosa and related Bantu languages is intertwined with tense. Rose et al. (2002:71) claim that the progressive forms denoting imperfective aspect are widespread in Bantu languages. It is widely acknowledged that in isiXhosa there are two sets of compound tenses, formed by the auxiliaries -be- and -ye-, which relate to the expression of the "ongoingness" of a past event. McLaren (1936) and Bennie (1939) claim that the former indicates that an action was ongoing in the recent past whereas the latter indicates that an action was ongoing in the remote past (McLaren 1936:90). The ongoingness of a future event is expressed by the auxiliary $-b a$ - followed either by the present indicative or the present participial mood of a verb (McLaren 1936:95). It is evident from the foregoing that compound tenses in which an auxiliary is followed by a lexical verb in the participial mood provide the prototypical strategy for expressing ongoing situations in isiXhosa ${ }^{2}$. Besides the use of compound tenses, the language does not possess specific morphology for progressive aspect to indicate that an event is taking place at the present moment.

\footnotetext{
${ }^{2}$ We are indebted to an anonymous reviewer for bringing this observation to our attention.
} 
In addition to compound tenses discussed above, there have been suggestions by some scholars (e.g. Doke 1931, Louw 1963 and Zotwana 1994) that the morpheme-sa-denotes progressive aspect in isiXhosa because it encodes the meaning "still" (e.g. ndisafunda 'I am still studying'). Upon closer examination, however, it seems that this morpheme fits the description of a "persistive" marker in the sense of Nurse (2003). Persistive aspect, which "denotes an activity that started in the past and is still ongoing at the time of reference" (Nurse 2003:99), is widespread across Bantu. Since the notion of 'still ongoing' seems to form the core meaning of the morpheme $-s a$ - in isiXhosa, it seems more appropriate to consider this morpheme as a marker of persistive rather than progressive aspect.

\section{The present study}

The present study is based on the intuitions of one Mandarin speaker (a native speaker of Mandarin and co-author of this work ${ }^{3}$ ) and questionnaire responses and interviews with ten L1 speakers of isiXhosa who were prompted to translate English sentences into isiXhosa. It should be pointed out that the English sentences were themselves translations from Mandarin. The questionnaire consisted of 138 sentences, 40 of which described situations in the present. The sentences consisted of verbs from different classes in terms of situation types (Vendler 1957) and covered other situation-internal factors (i.e. whether a situation is ongoing or habitual, completed or non-completed). The study was conducted in Grahamstown in the Eastern Cape. The questionnaire was administered in September 2011 to five subjects consisting of two university students, one lecturer and two high school teachers. As a follow-up, interviews were conducted with a further five participants consisting of two university students, two lecturers and one high school teacher. All the subjects, it should be emphasized, were highly proficient in isiXhosa and English.

Ideally, subjects should have been asked to translate directly from Mandarin to isiXhosa for this comparative study, but at the time there were no isiXhosa speakers who were highly proficient in Mandarin, nor Mandarin speakers whose isiXhosa proficiency was good enough to provide the data that was sought. This proved to be problematic for the research project for which the use of a third language (English) was deemed necessary. The problem arising from the use of a third language is that some of the translations may not have retained the original Mandarin meanings for which this study was seeking isiXhosa equivalents. For example, an English sentence such as "Sipho is wearing a shirt" is expressed by two different sentences in Mandarin, the first sentence meaning that Sipho is in the act of wearing the shirt and the second meaning that Sipho is in a shirt. In English, the sentence is ambiguous and yet it is this ambiguous sentence which would have to be translated into isiXhosa, not the distinct Mandarin sentences.

\section{An analysis of the encoding of present situations in Mandarin and isiXhosa}

The present includes all situations (i.e. states and events) which occur or exist in a time slot that overlaps with UT. Present situations may be those that are ongoing at UT or occur regularly in the time slot that includes UT (though they may not be ongoing at UT). We noted in (1) that for a verb like fundisa 'teach', isiXhosa makes no formal distinction between the ongoing event and the habitual one: both situations are marked by the absence of grammatical markers. What this means is that if Professor Cata was a teacher by profession, uttering (1) would be true

\footnotetext{
${ }^{3}$ It should be pointed out that other Mandarin speakers were consulted to check their judgments on the grammaticality of the Mandarin sentences.
} 
irrespective of whether at UT Professor Cata was watching soccer in a stadium, having a drink in a bar or conducting an isiXhosa lesson in a classroom. We also noted that in Mandarin the absence of any temporal markers in the sentence implies that the situation in question obtains on a regular basis, but definitely not at UT. What is clear is that with verbs of this type the two languages differ with respect to their encoding of whether at UT a situation is ongoing or not. We take up this point in the next section.

\subsection{Ongoing events}

Mandarin, unlike isiXhosa, invariably uses formal structures for differentiating ongoing situations from the non-ongoing ones. As a result, the sentence in (2), Cata jiàoshòu jiāo kăosà yŭ 'Professor Cata teaches isiXhosa', only refers to the fact that Professor Cata is an isiXhosa teacher by profession. The sentence would be appropriate to use if the speaker was introducing Professor Cata to a friend and was telling that friend what Professor Cata does; the sentence would be inappropriate to use if the speaker wanted to convey the sense that Professor Cata was, at the time of speaking, carrying out the act of teaching. To convey the idea that a situation is ongoing, the progressive particle zài has to appear in the sentence, as shown in (3).

$$
\begin{aligned}
& \text { Cata jiàoshòu zài jiāo kăosà yŭ. } \\
& \text { Cata Professor PROG teach Xhosa language } \\
& \text { 'Professor Cata is teaching isiXhosa.' }
\end{aligned}
$$

Here, the appearance of the particle zài indicates that Professor Cata is carrying out the act of teaching at speech time. It should be pointed out that the progressive aspect has quite a wide range of uses in Mandarin. It is not only used to refer to events that are taking place at speech time; it can also be used in reference to events that are assumed to be ongoing during a time span that includes the present moment, even if the event in question is temporarily not happening at UT. Thus it would be true to utter (3) in reference to a time span like jīnnián 'this year' (since it includes speech time) even if Professor Cata was not teaching at the time of speaking.

The particle zài indicates that an event is taking place at reference time or in a specific time slot which overlaps with reference time. It should further be pointed out that zài has restricted distribution: it can only be used with durative verbs and not punctual verbs. Specifically, zài is only compatible with activity and accomplishment verbs in terms of Vendler's (1957) and Dowty's (1979) classification of verb types. In other words, this particle cannot be used to describe states or achievements because states conflict with the non-stative feature of the progressive aspect, while achievements, being punctual, are incompatible with the durative feature of zài. Consequently, achievement verbs neither appear in the progressive form nor in the unmarked present form in Mandarin. If an achievement verb is used in the present form, it has to be accompanied by a temporal adverbial that has a habitual meaning. Consider the sentences in (4)-(6):

$$
\begin{aligned}
& \text { * tā zài dàodá Grahamstown. } \\
& \text { He PROG arrive Grahamstown } \\
& \text { 'He is arriving in Grahamstown.' }
\end{aligned}
$$


*tā dàodá Grahamstown.

He arrive Grahamstown

'He arrives in Grahamstown.'

tā měitiān zăoshang liù diăn dàodá Grahamstown.

He every day morning six o'clock arrive Grahamstown

'He arrives in Grahamstown at 6 o'clock every morning.'

In (4), the punctual property of the achievement dàodá 'arrive' does not agree with the grammatical feature of the progressive marker zài. Sentence (5) is also unacceptable because the punctual property inherent in dàodá is not compatible with 'eternal' or other enduring features associated with unmarked forms in Mandarin. Note that when a temporal adverbial with a habitual meaning is inserted into the structure, as in (6), the sentence is acceptable.

In isiXhosa, achievement verbs can freely occur in the present tense, i.e. in the unmarked form or with the prefix $-y a$ - which, as we noted earlier, is associated with the present tense. Consider the example in (7), taken from Zotwana (1994:84).

Ndi-ya-fik-a
I-PRS-arrive-FV
'I just arrived here.'

Our focus here is on the co-occurrence of a punctual verb with the prototypical present tense prefix $-y a$-. Note, however, that although the verb is in the present form, the sentence has a recent past reading (see also Du Plessis 1978 and 1986 for similar observations). The recent past reading, we would like to argue, does not arise because of the presence of the prefix $-y a-$. Rather, this reading arises from the inherent aspectual features of the verb. In other words, the verb being punctual renders the present tense reporting of the event in question as having occurred in a recent past (since the reporting happens after and not during the event).

Let us return to the encoding of present ongoing events in isiXhosa. Using primary tenses, as we have hinted above, the language does not have a specific morpheme to mark the progressive aspect for an event that is ongoing at UT. In order to distinguish an event that is taking place at UT from the one that happens regularly, isiXhosa speakers rely on the aspectual properties of the verb (see Du Plessis 1986) or on the use of temporal adverbials and deficient verbs. Take, for example, an activity verb such as pheka 'cook' in (8):

$$
\begin{array}{lllll}
\text { U-mama } & \text { w-am } & \text { u-phek-a } & \text { i-papa } & \text { yonke imihla. } \\
\text { CL1-mother } & \text { CL1-my } & \text { 1.SM-cook-FV } & \text { CL9-porridge } & \text { every day } \\
\text { 'My mother cooks porridge every day.' } &
\end{array}
$$

The occurrence of the temporal adverbial yonke imihla 'every day' rules out the progressive (or ongoing) reading in this sentence. If the temporal adverbial is omitted, the sentence becomes ambiguous in that both progressive and non-progressive readings are possible.

In addition to temporal adverbials, there are a number of deficient verbs (or auxiliaries) in isiXhosa which are used to distinguish an ongoing event from a non-ongoing one. There are a number of deficient verbs that normally have an ordinary substantive meaning, but when they 
appear before other verbs in sentences, they express particular semantic relations like temporal relations ${ }^{4}$. Take the following sentence in (9) as an example:

\begin{tabular}{|c|c|c|c|}
\hline U-Amanda & u-kholis-a uku-ya & e-Rhini & nge-moto. \\
\hline
\end{tabular}

In (9), the occurrence of the deficient verb kholisa is crucial to the habitual (and therefore nonprogressive) reading of this sentence. Without kholisa, the sentence can also be interpreted as describing an ongoing event, i.e. that at UT Amanda is driving a car to Grahamstown. In some cases the distinction between an ongoing activity and a habitual one is made on the basis of one's knowledge of the world or context. Consider the following sentences in (10) and (11):

$$
\begin{aligned}
& \text { U-Sipho u-ty-a uku-tya. } \\
& \text { CL1-Sipho } 1 . \text { SM-eat-FV CL15-food } \\
& \text { 'Sipho eats/is eating food.' }
\end{aligned}
$$

$$
\begin{aligned}
& \text { U-sipho u-ty-a i-pizza. } \\
& \text { CL1-Sipho 1.SM-eat-FV CL9-pizza } \\
& \text { 'Sipho eats/is eating pizza.' }
\end{aligned}
$$

In principle, both (10) and (11) ought to be ambiguous in that, in the absence of temporal adverbials or auxiliaries, each sentence can refer to either an ongoing event or a habitual one. Note, however, that in the case of (10) a habitual reading is less likely since it is common knowledge that human beings eat food, so the habitual reading of $<$ SIPHO EAT FOOD $>$ does not convey any new information. The more likely reading of (10) would thus be the one in which the activity is ongoing at speech time. By contrast, the sentence in (11) does not have such a restricted reading because it is not universally expected that Sipho eats pizza. This means that both the progressive and habitual readings of (11) would constitute new information. The ambiguity of this sentence can only be resolved by contextual cues. Such problems do not arise in Mandarin, where the particle zài obligatorily appears in sentences that denote ongoing events and disappears from sentences which describe regular or habitual events.

\subsection{Present states}

In the preceding section we noted that the progressive particle zài in Mandarin can only be used to describe events but not states due to the stativity of states that conflicts with the non-stative feature of the progressive aspect (Comrie 1976:35). In order to describe a state that obtains at UT or in a time slot that overlaps with UT, the particle zhe is used. This particle, which is defined as a durative aspect morpheme ${ }^{5}$, is used to describe states. Specifically, zhe expresses the idea that a state which obtained before reference time continues to obtain at reference time

\footnotetext{
${ }^{4}$ For a detailed description of each deficient verb, see for example McLaren (1936:136-138) and Bennie (1939:128-130).

${ }^{5}$ See for example Lü (1943), Chen (1980), Zhu (1982) and Dai (1997).
} 
(which could be UT) and will end after reference time if there is an end ${ }^{6}$. Consider the sentences in (12) and (13):

(12) Sipho chuān zhe yīfu.

Sipho wear DUR clothes

'Sipho is wearing clothes.'

(13) Sipho chuān yīfu.

Sipho wear clothes

'Sipho wears clothes.'

In (12), zhe indicates that at speech time Sipho is dressed in clothes. This sentence would be appropriate to describe a situation in which Sipho was in a state of being fully dressed. The sentence would, however, be inappropriate if it were used to describe a situation in which Sipho was in the act of putting on his clothes or to assert the fact that Sipho has the habit of being dressed in clothes. In order to express the idea that Sipho has the habit of being dressed in clothes (as opposed to being naked), the particle zhe has to be deleted, as shown in (13). If the speaker wants to express the idea that Sipho is in the act of dressing himself, then (14) has to be used.

(14) Sipho zài chuān yīfu.

Sipho PROG wear clothes

'Sipho is putting on clothes.'

Interestingly, in isiXhosa the distinction between the state of being dressed and the act of putting on clothes can be made by altering the form of the verb. Consider (15) and (16):

U-Sipho u-nxib-e ii-mpahla.

CL1-Sipho 1.SM-wear-PRF CL10-clothes

'Sipho is wearing clothes.'

(16) U-Sipho u-nxib-a ii-mpahla.

CL1-Sipho 1.SM-wear-FV CL10-clothes

'Sipho is putting on/wears clothes.'

\footnotetext{
${ }^{6}$ The particle $z h$, in addition to describing states, can also be used to describe events. When it occurs with events, it indicates that an event occurs simultaneously with another. In such sentences, zhe appears in the first VP of a serial verb construction and the event marked by zhe provides the background for the foregrounded event. For example,

(i) Sipho tīng zhe yīnyuè chī fàn.

Sipho listen DUR music eat food

'Whilst eating, Sipho listens to music.'

Here, the particle $z$ he indicates that Event $1<$ SIPHO LISTEN TO MUSIC $>$ and Event $2<$ SIPHO EAT FOOD $>$ are happening at the same time. There are interesting similarities here between zhe constructions and isiXhosa participial mood constructions illustrated in (ii).

(ii) U-Sipho u-cul-a e-fund-a.

CL1-Sipho 1.SM-sing-FV PART-study-FV

'Sipho sings while studying.'

Space does not allow us to go into the details of participial mood constructions in isiXhosa. A detailed discussion of this phenomenon can be found in Davey (1973).
} 
In (15), the perfect suffix - $e$ appears on the verb, thus indicating that an event which occurred in the past is being referred to. However, the sentence is used to describe a present state - the state of Sipho being dressed in clothes. The verb morphology $-e$ (i.e. the perfect) does not directly refer to a present state; it indicates that the act of wearing (or putting on) clothes happened prior to UT but the effects of that act still obtain at speech time, and the sentence is consequently interpreted as meaning that Sipho is dressed in clothes (as opposed to being naked) at the time of speaking. It should be noted here that both (12) and (15) refer to a present state. What is interesting is that in Mandarin the focus is on the enduring nature of the state at speech time, while in isiXhosa the focus is on the relation between the present state of affairs and a previous event that caused the present state of affairs to obtain ${ }^{7}$. Now, if we look at (16) we see that this sentence can only be used to describe a situation in which Sipho is carrying out the act of putting on clothes (i.e. an ongoing situation) or the case in which Sipho has a habit of wearing clothes.

It is also interesting to note that isiXhosa has other stative verbs, such as lamba 'get hungry' and lala 'fall asleep', which behave like nxiba 'wear'. In order to express a present state referred to by such verbs, the perfect tense affix -e/ile has to be used. As noted above, in such cases e/ile does not directly refer to a present state, but rather indicates that a resulting state of a past event obtains at UT (see Simango 2003 for a related discussion). Consider the sentences in (17) and (18) to make this point more explicit:

U-Sipho u-lamb-ile.

CL1-Sipho 1.SM-get hungry-PRF

'Sipho is hungry.'

$$
\begin{aligned}
& \text { U-Sipho u-ya-lamb-a. } \\
& \text { CL1-Sipho 1.SM-PRS-get hungry-FV } \\
& \text { 'Sipho is getting hungry.' }
\end{aligned}
$$

In (17), the marker -ile indicates that the instance of getting hungry occurred before speech time and the result of that occurrence, that is, the state of being hungry, still obtains at UT. The sentence can thus be interpreted as simply referring to the present state that Sipho is hungry. By contrast, in (18) where there are no overt temporal markers, the sentence is interpreted as meaning that Sipho is in the process of becoming hungry at the time of speaking.

In Mandarin, the particle le, called the "perfect marker" (see Lü 1943, Wang 1943, Gao 1948, Chao 1968, Kwan-Terry 1979 and Klein 2000, among others), can also be employed to describe states. This particle is similar to the isiXhosa suffix - e/ile in the sense that it is also used to refer to a present state. The particle le differs from the isiXhosa suffix in the sense that the former emphasizes the change from a prior state to the present one, while the latter emphasizes the resulting state of a past event. In addition, the particle le, by comparison, has a wider distribution in that le is used not only

\footnotetext{
${ }^{7}$ In an extensive study, Simango (2013) demonstrates that the encoding of the persistence of the effects of a past situation is widespread in Bantu.
} 
with stative verbs but also with adjectives, while - e/ile only occurs as a verbal suffix and cannot occur with adjectives ${ }^{8}$. This is illustrated in (19) below:

Sipho pàng le.

Sipho fat PRF

'Sipho has become fat.'

In (19), there is no verb at all'. Here, the presence of the particle le does not only assert that Sipho is fat at speech time, but also indicates that at some point before speech time Sipho was not fat. In other words, the particle le refers to a state with its inception from a previous state. This point becomes clearer when contrasted with the sentence without the particle le, shown in (20):

(20) Sipho hěn pàng.

Sipho very fat

'Sipho is very fat.'

In (20), the sentence only refers to Sipho's present state; it says nothing about whether or not Sipho was fat prior to UT. What we see here is that present states in Mandarin are distinguished in terms of whether or not they contrast with a previous state. However, in isiXhosa, -e/ile indicates that an event took place in the past and its resulting state obtains at UT, thus it normally refers to the present state only. More examples are provided below to explicate the distinction between le and -e/ile:
Wo hao le.
I well PRF
(Mandarin)
'I am well.'

$$
\begin{aligned}
& \text { Ndi-phil-ile. } \\
& \text { I-be well-PRF } \\
& \text { 'I am well.' }
\end{aligned}
$$

Both (21) and (22) indicate that the state "being well" obtains at UT, however the Mandarin sentence also means the speaker was not well before UT whereas the isiXhosa sentence does not have such meanings. In other words, uttering (21) would be inappropriate if the speaker has been always in good health. In isiXhosa, however, uttering (22) would be appropriate so long as the speaker is in good health at UT, regardless of whether or not the speaker was ill prior to UT.

\subsection{Persistive situations}

In isiXhosa, there is the affix $-s a$ - which appears on the verb to indicate that a situation which obtained before reference time still obtains at reference time. This morpheme, as a reviewer has pointed out, is often referred to as a "progressive morpheme" since it denotes the ongoingness of a given situation. We follow Nurse (2003) in calling this morpheme a "persistive morpheme"

\footnotetext{
${ }^{8} \mathrm{In}$ isiXhosa, if a present state is described by an adjective, then it has to be in the unmarked form. For example,

(iii) $\mathrm{Ku}$-shushu kakhulu.

It-hot very

'It is very hot.'

${ }^{9}$ Note that lamba 'be hungry' is a verb in isiXhosa while pàng 'be hungry' is an adjective in Chinese.
} 
because it has "still" as the core of its meaning. It denotes the continued existence of situations (i.e. events and states) from a past time up to and including the reference time. It should be pointed out here that the persistive nature of situations expressed by $-s a$ - bears some similarity with but is different from what are understood as ongoing situations generally encoded by progressive aspect. A state or event marked by $-s a$ - may be conceived of as ongoing at speech time, just as a state or event marked by a progressive morpheme would. However, there is a difference between the two in the sense that $-s a$ - necessarily places the origins of a given situation as having arisen in a period preceding UT or another reference point, whereas the progressive places no temporal boundaries with regard to a given situation. Furthermore, the progressive aspect has to be compatible with the inherent aspectual features of the verb. For instance, states cannot normally occur in the progressive aspect form (Vendler 1957, Comrie 1976), however, the particle $-s a$ - is unrestricted in terms of situation types and can be freely used to express states. Consider the two sentences in (23) and (24):

(23) Ndi-sa-phil-a.

I-PERS-be well-FV

'I am still well.'

$$
\begin{aligned}
& \text { U-Sipho u-sa-fund-a isiXhosa. } \\
& \text { CL1-Sipho 1.SM-PERS-study-FV isiXhosa } \\
& \text { 'Sipho is still studying/still studies isiXhosa.' }
\end{aligned}
$$

In (23), the presence of $-s a$ - does not only indicate that the state $<$ BE WELL $>$ exists at UT, it also denotes that the state has been in existence before speech time. Hence, this sentence would be true only if the speaker has been in good health for some time, and has not just recovered from an ailment. Similarly in (24), the sentence could be interpreted as meaning that Sipho started studying isiXhosa in the past and has continued doing so at UT.

Mandarin does not have grammatical devices to express such persistive natures of situations. In order to convey the meaning that a situation still persists, lexical items in the form of temporal adverbials like hái and réngrán have to be used, as illustrated by the examples in (25) and (26).

Zhèlǐ rén hái hěn duō.

Here people still very many

'There are still many people here.'

(26) Sipho réngrán_ zài xué kăosà yǔ.

Sipho still PROG study Xhosa language

'Sipho is still studying isiXhosa.'

In (25), the adverb hái indicates that the state of "many people being here" existed before speech time and it persists at speech time. The adverb réngrán in (26) implies that the event $<$ SIPHO STUDY ISIXHOSA $>$ started before speech time and it is still ongoing at speech time.

\section{Concluding remark}

What this comparative study has shown is that two typologically distinct languages exhibit interesting similarities when it comes to encoding situations that occur in a specific time frame, 
namely the present. From a formal standpoint, it has been shown that both Mandarin and isiXhosa do not have overt grammatical features for locating situations in the present. In both languages the present is the unmarked or default temporal location; as a result, reference to situations situated therein does not require specific grammatical markers even though in both languages such markers appear when the reported event occurs in a time slot that excludes the present moment. In addition, in both languages the perfect form (e.g. le in Mandarin and -e/ile in isiXhosa) is used to denote states that obtain at the present time. This study has also revealed at least two significant differences between isiXhosa and Mandarin. First, it has been demonstrated that the two languages differ with respect to the degree to which they distinguish ongoing from habitual situations in which the temporal locations overlap with UT or the present moment. Whilst Mandarin makes this distinction unequivocally by the use of the progressive particle zai to denote ongoing events, isiXhosa generally makes no such distinction when primary tenses are used; the language, instead, relies on the use of temporal adverbials, contextual cues, or the use of deficient verbs in compound tenses to make the distinction. What is interesting though is that in both primary and compound tenses, ambiguity is preponderant in isiXhosa. Second, the study has shown that although both languages employ the perfect form to refer to present states, the languages differ with respect to how they deal with the relation between a present state and a previous state/event. In Mandarin, a current state is described in terms of whether it is contrastive to some previous state - through the use of the particle le or the particle $z$ he if the state has some duration which includes the present moment. In isiXhosa, on the other hand, a current state is sometimes described in terms of a previous event of which the effects obtain at UT, as is indicated by the appearance of the perfect suffix -ile/-e. The morpheme $-s a$ - is used to denote the persistence of a situation from a preceding period leading up to and including the present moment or some other reference time. In general terms, it seems that Mandarin places more emphasis on situation-internal properties of states/events in conveying temporal relations whereas isiXhosa places more emphasis on temporal locations themselves. This in itself is not surprising granted the fact that isiXhosa is a tense language (where location in time is richly encoded in the grammar) whereas Mandarin is a tenseless language (where aspectual properties play a greater role in encoding temporal relations). There are other differences in the way the two languages deal with past and future situations but that is a subject for another study.

\section{Acknowledgement}

An earlier version of this paper was presented at the 2013 Annual Conference of the Linguistic Society of Southern Africa at the University of Stellenbosch. We thank the participants at the conference for their encouragement and are particularly grateful to two anonymous reviewers for their critical comments and suggestions. All errors and shortcomings remain our responsibility.

\section{References}

Anderson, S.C. 1983. Tone and Morpheme Rules in Bamileke-Ngyemboon. Doctoral dissertation, University of California.

Bennie, W.G. 1939. A grammar of Xhosa for the Xhosa-speaking. Eastern Cape: Lovedale Press. 
Binnick, R.I. 1991. Time and the verbs: A guide to tense and aspect. Oxford: Oxford University Press.

Botne, R. and T. Kershner. 2008. Tense and cognitive space: On the organization of tense/aspect systems in Bantu languages and beyond. Cognitive Linguistics 19(2): 145-218.

Chao, Y.R. 1968. A grammar of spoken Chinese. Berkeley: University of California Press.

Chen, G. 1980. The usage of 'zhe' and the comparison between 'zhe' and the progressive in English. Studies of the Chinese Language (Zhongguo Yuwen)1: 379-390.

Chung, S. and A. Timberlake. 1985. Tense, mood, and aspect. In T. Shopen (ed.) Language typology and syntactic description. Volume III: Grammatical categories and the lexicon. Cambridge: Cambridge University Press. pp. 202-258.

Comrie, B. 1976. Aspect: An introduction to the study of verbal aspect and related problems. Cambridge: Cambridge University Press.

Comrie, B. 1985. Tense. Cambridge: Cambridge University Press.

Dai, Y.J. 1997. Aspect in modern Chinese. Hangzhou: Zhejing Education Press.

Davey, A.S. 1973. The Moods and Tenses of the Verb in Xhosa. MA thesis, University of South Africa.

Doke, C.M. 1931. Textbook of Zulu grammar. London: Longman.

Dowty, D.R. 1979. Word meaning and Montague grammar: The semantics of verbs and times in Generative semantics and in Montague's PTQ. Dordrecht: Reidel.

Dragunov, A.A. 1952. Studies on the grammar of modern Chinese language. Moscow: Academy of Science.

Du Plessis, J.A. 1978. IsiXhosa. Goodwood: Oudiovista Produksies.

Du Plessis, J.A. 1986. Present tense in Xhosa: What does it mean? South African Journal of African Languages 6(2): 71-73.

Du Plessis, J.A. and M. Visser. 1992. Xhosa syntax. Pretoria: Via Afrika.

Gao, M.K. 1948. The grammar of Chinese language. Beijing: Commercial Press.

Giorgi, A. and F. Pianesi. 1997. Tense and aspect: From semantics to morphosyntax. Oxford: Oxford University Press.

Guthrie, M. 1971. Comparative Bantu. London: Gregg Press.

Kenny, A. 1963. Action, emotion and will. New York: Humanities Press. 
Klein, W. 1992. The present perfect puzzle. Language 68: 525-552.

Klein, W. 2000. An analysis of the German 'perfekt'. Language 76: 358-382.

Kwan-Terry, A. 1979. Two progressive aspect markers in Chinese. In D.L. Nguyen (ed.) SouthEast Asian Linguistic Studies Vol. 4. Canberra: The Australian National University. pp. 213-232.

Levinson, S. 1983. Pragmatics. Cambridge: Cambridge University Press.

Li, C.N. and S.A. Thompson. 1981. Mandarin: A functional reference grammar. Berkeley: University of California Press.

Li, J.X. 1924. A new grammar of the Chinese national language. Beijing: Commercial Press.

Li, T.G. 2002. 'Zhe', 'le', 'guo' and the temporal expression in Mandarin. Studies in Language and Linguistics (Yuyan Yanjiu) 48(3): 1-13.

Louw, J.A. 1963. Handboek van Xhosa. Johannesburg: Bonapers Beperk.

Lü, S.X. 1943. Essentials of Chinese grammar. Beijing: Commercial Press.

McLaren, J. 1936. A Xhosa grammar. London: Longman.

Nurse, D. 2003. Aspect and tense in Bantu languages. In D. Nurse and G. Phillipson (eds.) The Bantu languages. London: Routledge. pp. 90-102.

Nurse, D. 2007. The emergence of tense in early Bantu. In D.L. Payne and J. Pena (eds.) Selected proceedings of the $37^{\text {th }}$ Annual Conference on African Linguistics. Somerville, MA: Cascadilla Proceedings Project. pp. 164-179.

Posthumus, L.C. 1988. Basis of tense analysis in African languages. South African Journal of African Languages 8(4): 139-143.

Reichenbach, H.1947. Elements of symbolic logic. New York: The Macmillan Co.

Rose, S., C. Beaudoin-Lietz and D. Nurse. 2002. A glossary of terms for Bantu verbal categories, with special emphasis on tense and aspect. Munchen: Lincom Europa.

Simango, S.R. 2003. Reanalysing past tense categories in Bantu. Malilime: Malawian Journal of Linguistics 3: 67-84.

Simango, S.R. 2013. Persistence and remoteness in the Bantu past tense. Paper presented at the $5^{\text {th }}$ International Conference on Bantu Languages, 12-15 June 2013, Paris.

Smith, C. and M. Erbaugh. 2005. Temporal interpretation in Mandarin. Linguistics 43: 713-756. 
Timberlake, A. 2007. Aspect, tense, mood. In T. Shopen (ed.) Language typology and syntactic description. Volume III: Grammatical categories and the lexicon. Cambridge: Cambridge University Press. pp. 280-333.

Vendler, Z. 1957. Verbs and times. Philosophical Review 56: 143-160.

Wang, L. 1943. The grammar of modern Chinese language. Beijing: Commercial Press.

Wang, S.M. 1981. The category of tense and aspect in Mandarin. Journal of Qiqihaer Normal University 3: 65-76.

Yakhontov, B.B. 1957. The categories of verbs in Chinese language. Translated by C. Konglun. Beijing: Zhonghua Book Company.

Ye, F.S. and L.J. Xu. 1997. The outline of linguistics. Beijing: Peking University Press.

Zhang, J.Q. 1998. On the tense and aspect structures in modern Chinese language. Journal of Linguistic Research (Yuwen Yanjiu) 68(3): 17-25.

Zhu, D.X. 1982. Lecture sheet on grammar. Beijing: Commercial Press.

Zotwana, Z. 1994. Xhosa in context. Cape Town: Vlaeberg Publishers. 